\title{
СОмо О
}

\section{OPEN BANIKING IMPACTARÁ O FUTURO DO}
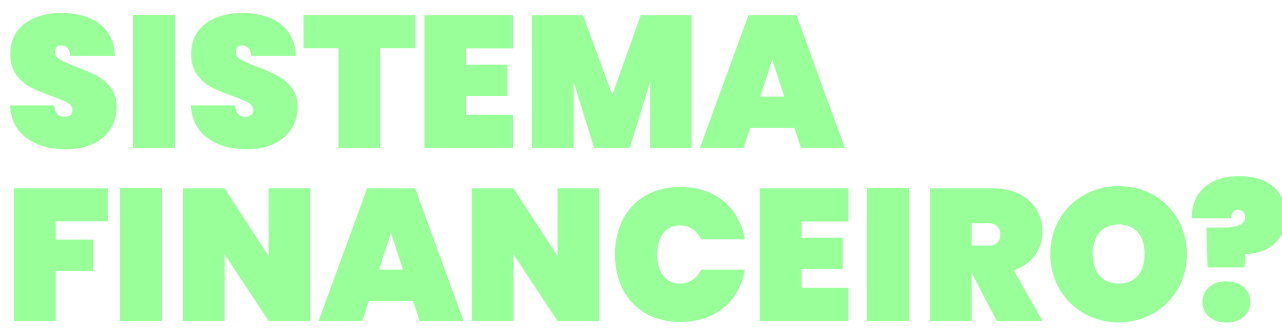

Tiago Aguiar

\section{CONCEITO}

De forma resumida, o Open Banking é um novo conceito de sistema financeiro. A partir de uma legislação específica, que prevê a regulação do Banco Central, e mediante o prévio consentimento dos clientes, os bancos passam a compartilhar as informações de cadastro e de transações desses usuários com diferentes instituições, além de permitir a movimentação das contas bancárias a partir de diferentes plataformas e não mais apenas pelo aplicativo ou site da própria instituição financeira.

O ponto de partida do Open Banking é o cliente. Como dono, é ele que pode gerir seus próprios dados - que hoje estão armazenados dentro dos bancos. Os usuários poderão determinar quais dados querem compartilhar e para quem.

De acordo com a Resolução Conjunta BCB/CMN nº 1, de 4 de maio de 2020, as instituições financeiras devem deixar públicas suas informações de produtos e serviços com os valores e as taxas cobradas, bem como os endereços de locais de atendimento e horários.

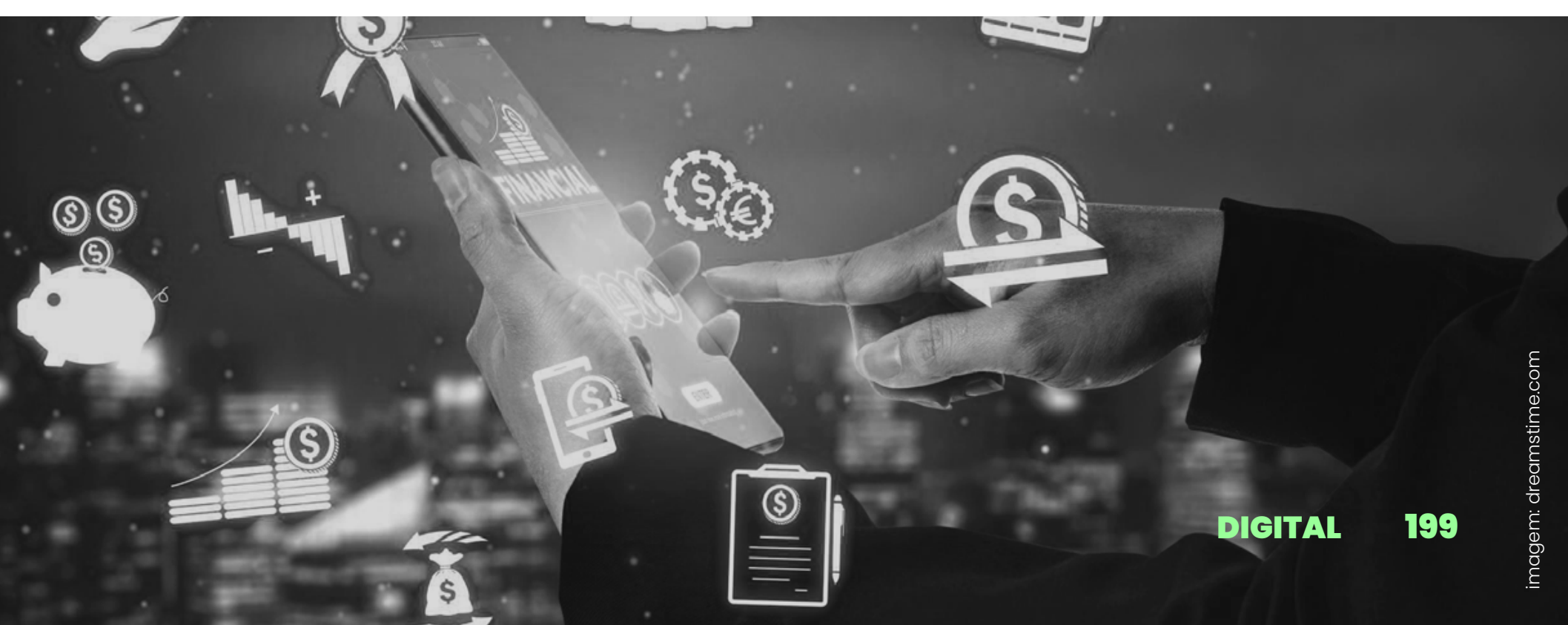


Também, devem permitir que as pessoas compartilhem suas informações cadastrais e financeiras. Por fim, permitir que terceiros iniciem/realizem consultas e/ou transações diretamente da conta de um cliente.

Assim, com a permissão de cada correntista, aplicativos externos poderão se conectar diretamente às plataformas das instituições financeiras e solicitar os dados dos clientes e/ou realizar transações em nome do cliente.

Exemplificando, um cliente bancário poderá dar permissão a um aplicativo de outra instituição regulada pelo Bacen, para que acesse seu histórico de transações do último ano e, com base nessa análise, outra ferramenta poderá sugerir um produto financeiro compatível com sua renda. As aplicações do Open Banking são diversas e, mais adiante, neste artigo, veremos alguns casos de uso possíveis.

\section{Além de compreender • conceito do Open Bonking e parre que ele servirú d̀ secied ade, vale dizer tambếm que • Open Banking possui 3 pilleres fundomentais: (1) padronizeçấ०, (ii) reguleģãoe, principalmente, (iii) coleborç̧ão. $\odot$ Benco Gentral do Brasil tem um peppel fundelmentel no que diz respeito

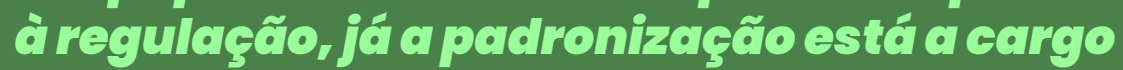 das associç̧öes representativas do setor fincheeiro (sejelm elas representativas des instituiçōes finch ceircrs, de erédito ou das fintechs). Porém, para que o Open Banking possa realmente trazer beneff́cios para a seciedade, é a coleborç̧ão que exercerá pepel fundermentel neste movimento.}

Diferentemente de um meio de pagamento, que transforma a experiência do usuário no check-out, o Open Banking tem potencial para transformar a sociedade como um todo. Mas, para que esse objetivo seja atingido, não pode ser encarado como um exercício de compliance. É fundamental que as diversas instituições participantes colaborem entre si, resolvendo desafios que afligem o dia a dia da população e fazendo com que produtos financeiros possam chegar aos financeiramente excluídos. 


\section{DIFERENÇAS ENTRE O MODELO BRASILEIRO E O MUNDO}

No Brasil, a legislação sobre Open Banking foi oficialmente publicada em 4 de maio de 2020, determinando 13 bancos, pertencentes aos segmentos prudenciais 1 e 2, estarem em produção com todas as 4 fases previstas até o final de 2021. Segundo o Bacen, o objetivo do novo sistema é aumentar a eficiência, diminuir o custo para prover serviços financeiros e promover maior competição, tudo isso em benefício do consumidor de produtos de crédito, de investimento e de pagamentos.

No Reino Unido, o Open Banking tem raiz em uma investigação conduzida pela Autoridade de Competição Monetária (CMA) sobre a concorrência no mercado bancário que, por sua vez, concluiu que a melhor maneira de estimular o mercado financeiro era abrir os dados bancários a uma gama muito mais ampla de terceiros provedores de serviço (conhecidos como "TPPs"). Isto quer dizer que, no Reino Unido, atendidos diversos requisitos e certificações, e por meio de processos de "lista de permissões", instituições não reguladas também podem fazer parte do ecossistema de Open Banking inglês (e.g., as Fintechs).

No caso da Comunidade Europeia, o parlamento publicou, em 2015, uma diretiva conhecida como PSD2, que se aplica a todos os provedores de conta de pagamento. Porém, diferentemente do Brasil ou do Reino Unido, o PSD2 não exigiu a criação de padrões comuns de integração (e.g., API padronizadas). Sendo assim, os bancos disponibilizaram seus dados por meio de diferentes padrões técnicos. Isso impôs uma camada adicional de complexidade para as ferramentas de agregação de contas, por exemplo. Mas, assim como na implementação no Brasil, o PSD2 só abre o acesso aos dados transacionais do cliente para instituições específicas que também são reguladas.

Há também outras iniciativas de Open Banking em diversas partes do mundo. Vale trazer aqui a experiência australiana, que foi lançada em julho de 2019, fruto de um projeto ligado à Proteção de Dados dos Consumidores, conduzido juntamente com a participação da Autoridade de Competição. Neste caso, a obrigação de abertura recai sobre os quatro maiores bancos australianos, os quais devem conceder acesso às transações de cartão de débito e crédito, conta corrente, crédito imobiliário e crédito pessoal.

Noutro espectro do movimento de abertura, há países que estão voluntariamente adotando o Open Banking. É o caso da Nigéria, onde, em 2017, um grupo de banqueiros e fintechs se juntaram para adotar regras comuns de abertura de dados. Já em Singapura, a adoção também é voluntária, porém quem está conduzindo o processo é a Autoridade Monetária Nacional.

Por fim, é notório observar que a maior diferença do modelo brasileiro para o internacional está no fato do formato que está em implementação no Brasil ser mais abrangente do que alguns países, pois engloba não somente produtos essencialmente bancários, mas também operações de câmbio, previdência privada, investimentos e seguros. É o chamado Open Finance. 


\section{É aqui que reside o verdadeiro potencial dos serviços bancários abertos, pois o acesso adequado aos dados de uma pessod permite que terceiros eriem aplicativos e produtos mais poderosos, personalizados e customizados para os diversos nichos e segmentos sociais.}

Rapidamente, veremos surgir soluções como:

1. Agregadores de contas bancárias.

2. Ferramentas de comparação de preços de produtos bancários.

3. Soluções de crédito usando dados bancários pessoais.

4. Produtos de seguros com preços dinâmicos com base em dados bancários.

5. Aplicativos automatizados de micropoupança e microinvestimento.

O público-alvo dessas soluções irá desde uma pessoa física comum às grandes corporações, passando principalmente pelas micro e pequenas empresas e pelos microempreendedores individuais (que confundem conta pessoal com o negócio). Porém, acima de tudo, o Open Banking tem o poder de incluir perto de 45 milhões de brasileiros "desfinanciados" - pessoas que hoje não possuem acesso a crédito por não ter histórico financeiro suficiente que forneça dados básicos para uma análise de risco melhor, sem o qual não conseguem obter um financiamento para comprar, por exemplo, um imóvel, carro ou eletrodomésticos.

Para uma pessoa física que possui diversas contas bancárias, o Open Banking permitirá a ela verificar todas as suas transações numa única interface através dos aplicativos agregadores de contas, os quais inclusive poderão movimentar recursos entre uma conta e outra, caso o saldo fique negativo em uma determinada instituição. Esse mesmo aplicativo, com uma inteligência artificial embutida, poderá ajudar o indivíduo a organizar melhor suas finanças, sugerindo produtos financeiros com melhores taxas ou ainda ajudá-lo a economizar.

No que diz respeito aos micro, pequenos e médios empresários, o Open Banking permitirá a eles controlar melhor seu fluxo de caixa, conciliar pagamentos, gerir estoques e integrar todas essas informações com seu prestador de serviço contábil, o qual terá à sua disposição todas as informações transacionais da empresa, não sendo mais necessário exportar diferentes arquivos de diferentes bancos para que sejam consolidados em uma única visão. Com informações mais precisas, será mais fácil para o empresário conseguir crédito com taxas menores. 


\section{(9) (3) (9)

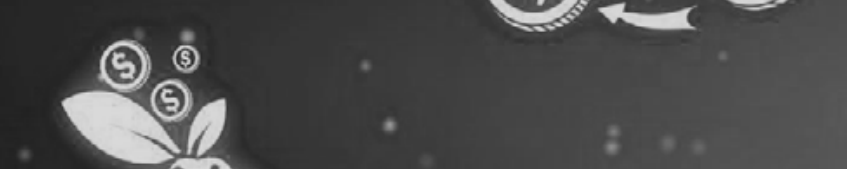

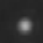

Por fim, forc do Brasil jă essistimos a diversas iniciativas, liderades por fintechs, junto a० públice desbancerrizado. Empréstimos pessoc-pessod, anćllise de erédilio a partir de modelogens nãoortodoxas, basedda em algoritmos avanģados, estâ॰ permitind o que sejam ineluf́dos no sistema de erédito milhöes de pesseas que dté então ficavam à margem do sistema fincheeiro. Inicictivas come bernces socicis e secied cdes de erédito estão levando recursos atée à portà das eomunidades.

\section{MODELOS DE NEGÓCIO dOS BANCOS}

\section{O modelo banećrio do futuro será o marketplece banking.}

Pelo menos é isso que a maioria dos consultores do setor financeiro acreditam. Vamos entender abaixo o porquê.

Até 2021, os bancos trabalhavam num modelo vertical de produção e venda. Ou seja, o banco criava seus produtos, distribuía e os vendia por meio de seus próprios canais (agências, ATMs, internet e mobile banking e correspondentes bancários). Porém, a partir do Open Banking, o modelo de distribuição irá mudar completamente. Produtos financeiros poderão ser distribuídos dentro de um ecossistema de fornecedores, usando interfaces e marcas distintas do produtor.

Assim, o tradicional modelo de negócios será transformado em um mercado baseado em plataformas com uso intensivo de dados, onde diversos provedores de serviços financeiros irão concorrer continuamente para oferecer aos clientes produtos personalizados com as melhores taxas. A batalha estará na interface e na experiência de uso. A grande questão será: por meio de qual solução, aplicativo ou website o cliente irá operar? 

eliente parra outra interface.

A primeira opção é o banco continuar sendo "provedor completo de serviços" (full services provider). Esse modelo representa o status quo, no qual o banco continua a ofertar uma gama de serviços financeiros, tendo o Open Banking como uma obrigação regulatória. Essa pode ser uma estratégia a ser adotada pelos grandes incumbentes, os quais possuem força extraordinária de marca e uma base gigante de clientes. Porém, para se manterem competitivos, esses players terão que evoluir no uso de dados dos clientes - os quais estão dispersos em diversos silos dentro da organização - de forma a oferecer produtos mais customizados, melhor experiência de usuário e preços competitivos.

A segunda opção é se tornar um serviço público (utility). Neste modelo, o banco incumbente perde a interface com o usuário final e passa a prestar serviços para os fornecedores que controlam a experiência de uso. Aqui, os bancos podem prestar serviços de armazenamento de dados, gateways de pagamento, prover informações cadastrais, know your custormer, vender score de crédito, fazer checagem contra lavagem de dinheiro (PLD), etc. Isso é análogo à receita obtida pelas empresas de telecomunicações para permitir o streaming e o fornecimento de conteúdo de mídia por meio de sua infraestrutura.

Atuar como "Fornecedor de Produtos" (product supplier) é a terceira opção. Neste molde, o banco foca em sua competência e know-how como desenvolvedor de produtos financeiros, complexos ou não, renuncia à interface com o cliente e distribui seus produtos em plataformas de terceiros. A desvantagem desta variante é que os produtos bancários estarão expostos à maior concorrência do que hoje encontram via distribuição vertical, o que pode pressionar as margens de receita para baixo.

Por fim, a quarta opção é ser um "Everyday Bank", ou seja, ser titular da interface. Neste modelo, os bancos mantêm o controle da experiência de uso, permanecendo como o principal ponto de interação do cliente com suas finanças, e muito além. Aqui, o banco expande o ecossistema e agrega valor através de produtos de terceiros. Passa a ter uma proposição holística de serviços financeiros integrada com serviços/produtos de terceiros, como das fintechs, varejistas e das plataformas de investimentos. Permitem que os clientes se beneficiem de maior transparência de preço e escolham entre uma gama de serviços concorrentes entre si. 
Porém, a opção acima exigirá uma reforma no atual modelo de negócio dos bancos, o que poderá diminuir a margem obtida mediante cobrança de juros, visto que o principal negócio deixa de ser a captação de depósitos à vista e empréstimo para a obtenção de receita via taxas de intermediação pelo uso da plataforma.

Os bancos, ao estabelecerem um ecossistema de fornecedores, poderão estar bem posicionados para centralizar todo o processo de compra por meio de interfaces que forneçam uma experiência única e abrangente ao cliente.

Existem vários exemplos possíveis, como os processos nada agradáveis da compra, venda, aluguel e reforma de um imóvel, incluindo diversos players, desde o próprio banco a imobiliárias, seguradoras, advogados, casas de material de construção, etc. Os bancos poderiam reunir agentes imobiliários, advogados e seguradoras em uma única interface para fornecer um serviço completo fim a fim e, ao mesmo tempo, aproveitar os dados transacionais do cliente para lhe sugerir as melhores opções de imóvel, o bairro mais adequado; tudo de acordo com o perfil e poder aquisitivo do usuário.

\section{CONCLUSÃo}

- Open Bernking nivela ๑ cempo concerrencial perra que fintechs e bigtechs atuem no merecdo que, cté então, era exclusivo das instituiģôes fincheeiras. Mas se por um Iadoele equilibra o jogo, por outro, tcimbém permite que as instituiçêes mais tradicioncis se reinventem para, assim, permanecerem relevantes e competitivas na nova economia digitel.

Dado seu acesso a depósitos, marca forte e experiência, os bancos incumbentes que abraçarem o mercado financeiro aberto têm uma oportunidade real de vencer a batalha pela interface com o cliente e, portanto, pelo relacionamento.

Uma pesquisa realizada em 2019, pela Ipsos, em 21 países, com 21 mil entrevistados, revela que $70 \%$ destes confiam mais em um banco estabelecido para oferecer serviços e produtos de Open Banking, enquanto que apenas $11 \%$ confiam em fintechs para os mesmos serviços. 
A eapacidade de explorar e usar os dados (que jä possuem) do cliente em propostas inovadoras e mais individualizadas será fundamental no futuro do sistema bancário aberto. Para isso, bancos deverão quebrar os silos internos de dados de produtos, a fim de enxergar $\bullet$ cliente em todas as suas interações com a instituição. Junte-se a isso algoritmos inteligentes, aprendizado de máquina, ancólises cognitivas e score baseados nãosó em históricos financeirros, mas também em padröes de comportamento social.

Outras mudanças fundamentais de comportamento e cultura que os bancos deverão abraçar são a mentalidade do "falhe rápido e aprenda rápido" e uma forma de trabalhar de maneira ágil, que incentive a experimentação e admita o erro.

\section{Tiago Aguicr}

Superintendente de Novas Plataformas na TecBan

Tiago Aguiar é Superintendente de Novas Plataformas na TecBan. É advogado, mestre em Direito, pela PUC-SP, e tem especialização em Negócios Internacionais, pela New York University.

Empreendedor em série, já fundou 5 empresas - incluindo uma startup para lavar carros sem água, que o levou a participar e ganhar o reality show Aprendiz 4 - O Sócio -, e foi mentor/consultor de outras dezenas. Tem 20 anos de experiência, incentivando e ajudando pessoas a montarem negócios e empresas a inovarem.

É autor do livro "Dê um startup na sua vida", publicado pela Ed. Saraiva, em 2013. 